Zeyin He

Weiyi Tang

Tengjiao Lin

Sun Shizheng

https://doi.org/10.21278/TOF.42404

ISSN 1333-1124

eISSN 1849-1391

\title{
MODAL ANALYSIS AND AN EXPERIMENTAL STUDY INTO A MARINE GEARBOX FEATURING CONFLUENCE TRANSMISSION
}

\begin{abstract}
Summary
An approach to calculating vibration modal characteristics of a marine gear system featuring confluence transmission based on the theoretical and the experimental modal analysis is given in view of the fact that it is difficult to accurately determine the modal data of the system because of its complex vibration mechanism. Firstly, a dynamic finite element model of a coupled gear-rotor-bearing-housing system is developed by combining the gearbox transmission model with the gearbox housing model using the modal parameter identification data. Then, the modal frequency and the mode of vibration can be obtained. In fact, the proposed model can provide a faster approach to analysing the mode of the gear system vibration. Finally, experimental testing of the mode of vibration is performed on the experimental prototype to verify the rationality of the theoretical analysis. A comparison of the two sets of results shows that the experimental results are in good agreement with the computational results, with a maximum error of $6.3 \%$.
\end{abstract}

Key words: $\quad$ Marine gear system, modal analysis, modal experiment, FEM

\section{Introduction}

A gear system is a complex mechanical system which consists of a transmission system (gears, shafts, bearings, etc.), and a housing. Thus, different modes of the gear system vibration can be caused by nonlinear factors, such as the dynamic incentive of tooth meshing during the gear system operation, the vibration of the engine or electric motor, and the load fluctuation. When the vibration frequency is in accord with the natural frequency of the gear system, the system resonance will occur. In that case, severe vibration could seriously affect the normal operation of the system. Hence, obtaining accurate vibration modal characteristics of the gear system is particularly important.

Recently, many scientists carried out extensive research into the vibration modal characteristics of mechanical systems [1-2]. Wang [3] developed an analytical model of a bevel planetary gear transmission system to investigate the modes of vibration based on the inductive method. Ma [4] mainly focused on the natural characteristics of a two-stage helical gear transmission system under different modal coupling action. $\mathrm{Bu}$ [5] proposed a 
generalized dynamic model for a herringbone planetary gear transmission system to investigate its modal properties; the model includes the axial vibration of two helical ring gears and three planar degrees of freedom for the carrier and all the gears. Han [6] studied the modal parameters based on the theoretical and experimental modal analysis taking a one-stage gear transmission system as the research object. Based on that, our group carried out an experimental modal study into a complex marine gearbox to obtain the modal frequency [7]. However, our group found out that the modal parameters can not be completely obtained only by using the experimental modal analysis, especially in the case of a marine gearbox with larger physical dimensions, because of the complex vibration mechanism. At present, there are a few researchers who can obtain accurate values of the mode of vibration of a large complex gear system through the integration of parameter identification data based on the theoretical and the experimental modal analysis [8].

Therefore, the main objective of this paper is to develop a dynamic model of coupled gear-rotor-bearing-housing system to study the modal characteristic of vibration using the modal parameter identification data. Experimental testing of the modes of vibration is performed on the experimental prototype to verify the rationality of the theoretical analysis.

\section{Calculation of the modes of the gear system vibration}

This section we will take a GW marine gearbox as an example; the GW represents a series of codes of a marine gearbox with a clutch, which is divided into a transmission system and a housing. A dynamic model of a coupled gear-rotor-bearing-housing system is developed by combining the transmission system with the structural one by means of support bearings between the two systems [9].

\subsection{Mathematical model of the modes of vibration}

Figure 1 shows a diagram of the marine gearbox transmission structure. It is a kind of a double engine concurrence marine gearbox with a Power Take-Off (PTO) shaft. The gearbox is composed of two identical input shafts, I and II, an output shaft and a PTO shaft.

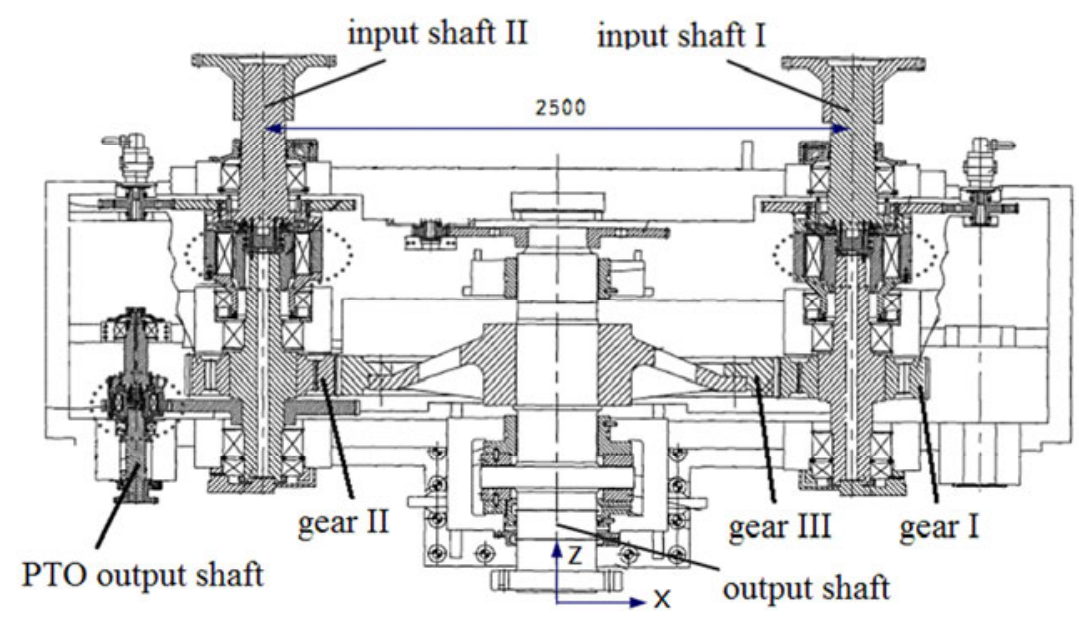

Fig. 1 Diagram of the geared transmission system

The geared transmission parameters of this marine gearbox are as follows: tooth number of gear I and II $z_{1} / z_{2}=41 / 41$, tooth number of gear III $z_{3}=161$, normal module $\mathrm{m}_{\mathrm{n}}=12 \mathrm{~mm}$, normal pressure angles $\alpha=20^{\circ}$, helical angle $\beta=20^{\circ}$, centre distance $a=1250 \mathrm{~mm}$, elasticity modulus of gear $E=2.06 \times 10^{11} \mathrm{~Pa}$, density $\rho=7.85 \times 10^{3} \mathrm{~kg} / \mathrm{m}^{3}$, Poisson's ratio $\mu=0.3$, input rotational speed $n=800 \mathrm{r} / \mathrm{min}$, power $P=200 \mathrm{~kW}$. 
According to the design parameters of the gear system, an accurate solid model of the gear pairs is built with the help of the Gear Modification Technology Engineering (GEMTE) software which is designed and developed by our group [10]. The GEMTE software can be used to obtain the codes for building a solid and a meshing model of a gear pair and to import them in the ANSYS. The gear meshing stiffness in the transmission system can be simulated using spring elements, whose stiffness value can be obtained using the GEMTE software. In GEMTE, the finite element method is used. For example, we can build the finite element model and obtain the contact force and deformation of a gear pair using the GEMTE software. The meshing stiffness of gear pairs can be obtained by dividing the force by deformation. The relationship between the transmission system and the structural system can also be simulated using the spring elements between the bearing housing and the shafts, which will define the stiffness in the radial and the axial direction. It is well known that the bearing stiffness has an important effect on the gear system dynamics. Therefore, it is of crucial importance to correctly identify the bearing stiffness parameters. As shown in Fig. 1, there are 13 bearings in the GW gearbox, 3 bearings on the output shaft, 5 bearings on the input shaft I and 5 on the input shaft II. The solid model of the gearbox is shown in Fig. 2(a).

The modal analysis method for parameter identification is described as follows: firstly, equations of joint parameters can be obtained based on the inverse relationship between the system dynamic stiffness matrix and the frequency response function matrix. Then, the stiffness and damping of gear pairs and bearings are obtained. Finally, the bearing stiffness is calculated using the Romax software in order to ensure the rationality of the model since the stiffness and damping of gear pairs cannot be obtained using the method of parameter identification. Thus, the results in Table 1 are obtained using the parameter identification method and the missing parameters are obtained by the Romax software.

Table 1 Results of bearing stiffness

\begin{tabular}{|c|c|c|c|c|}
\hline \multirow{2}{*}{ Position of bearings } & \multirow{2}{*}{ No. } & \multicolumn{3}{|c|}{ Bearing stiffness $/ \mathrm{N} \cdot \mathrm{m}^{-1}$} \\
\hline & & $X$-direction & $Y$-direction & $Z$-direction \\
\hline \multirow{5}{*}{ Input shaft I } & 1 & $1.2 \times 10^{9}$ & $7.1 \times 10^{8}$ & $6.5 \times 10^{8}$ \\
\hline & 2 & $4.3 \times 10^{9}$ & $7.2 \times 10^{9}$ & - \\
\hline & 3 & $4.1 \times 10^{9}$ & $3.3 \times 10^{8}$ & - \\
\hline & 4 & $4.9 \times 10^{8}$ & $9.1 \times 10^{7}$ & - \\
\hline & 5 & $8.5 \times 10^{8}$ & $6.4 \times 10^{8}$ & - \\
\hline \multirow{3}{*}{ Output shaft } & 6 & $4.5 \times 10^{8}$ & $5.1 \times 10^{8}$ & - \\
\hline & 7 & $6.8 \times 10^{8}$ & $1.3 \times 10^{9}$ & $8.4 \times 10^{9}$ \\
\hline & 8 & $4.8 \times 10^{8}$ & $5.6 \times 10^{8}$ & - \\
\hline
\end{tabular}

The dynamic finite element analysis model of a gear system with a total of 429203 elements and 145061 nodes, as shown in Fig. 2(b), is established including the gearbox housing, gears, bearings and transmission shafts, and the support between the shafts and the bearings. 


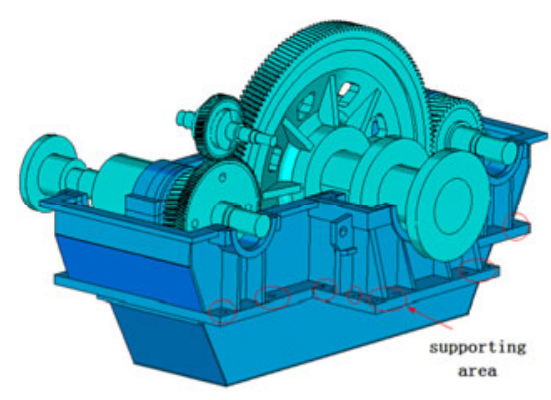

(a) solid model

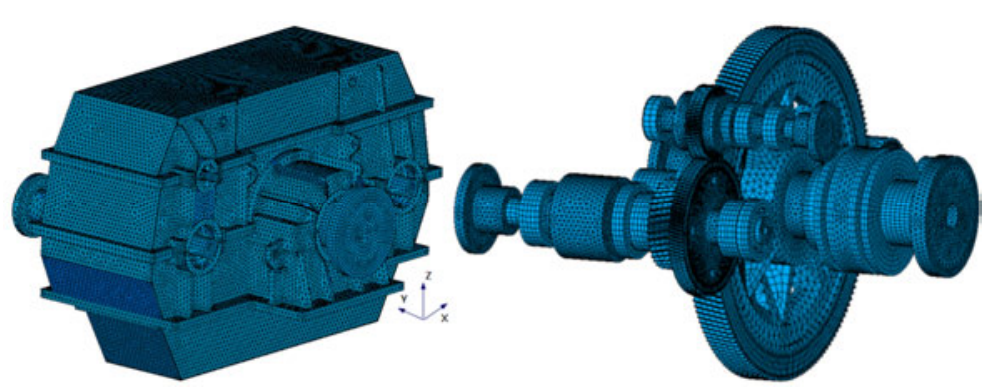

(b) finite element model

Fig. 2 Modal analysis models

\subsection{Intrinsic modal analysis}

The intrinsic modes would be analysed in this section based on the Block Lanczos method. For all the numerical results proposed in this paper, a 3\% viscous damping ratio is considered. The finite element modal analysis of the considered marine gear system is calculated with a fully constrained base plane of the gearbox, as shown in Fig. 2(a). The finite element modal analysis is carried out using the commercial finite element analysis software (ANSYS). The first 10 modes of the coupled gear-rotor-bearing-housing system are obtained as listed in Table 2. The first two modes are shown in Fig. 3.

Table 2 The first 10 modes of the considered marine gear system

\begin{tabular}{|c|c|c|}
\hline Mode no. & Frequency $/ \mathbf{H z}$ & Description of the mode shape \\
\hline 1 & 14.7 & Gear III torsion around the $Z$-axis \\
\hline 2 & 62.7 & Gear I torsion around the $Z$-axis \\
\hline 3 & 79.9 & Gear III wobble around the $X$-axis \\
\hline 4 & 81.5 & Gear II torsion around the $Z$-axis \\
\hline 5 & 89.1 & Gear III wobble around the $Y$-axis \\
\hline 6 & 105.0 & Gear III translation around the $Z$-axis \\
\hline 7 & 112.4 & Gear I and gear II wobble around the $Y$-axis \\
\hline 8 & 113.6 & Gear III bending \\
\hline 9 & 126.4 & Complex deformation \\
\hline 10 & 132.4 & Complex deformation \\
\hline
\end{tabular}

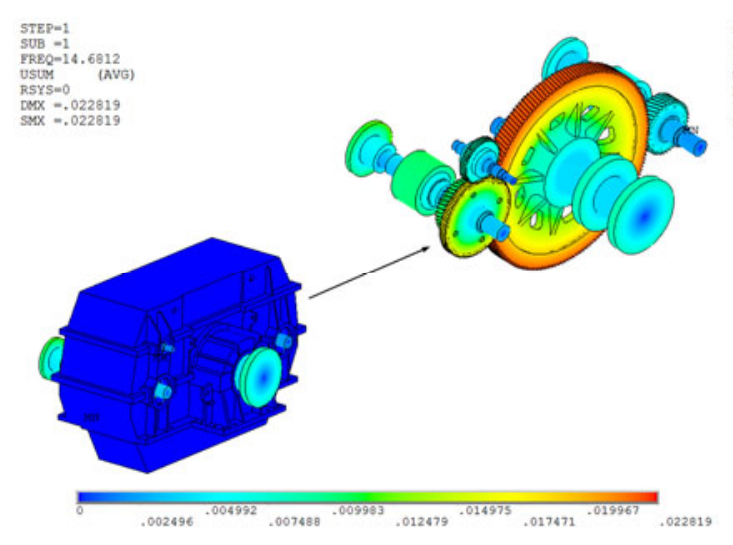

(a) Mode no.1

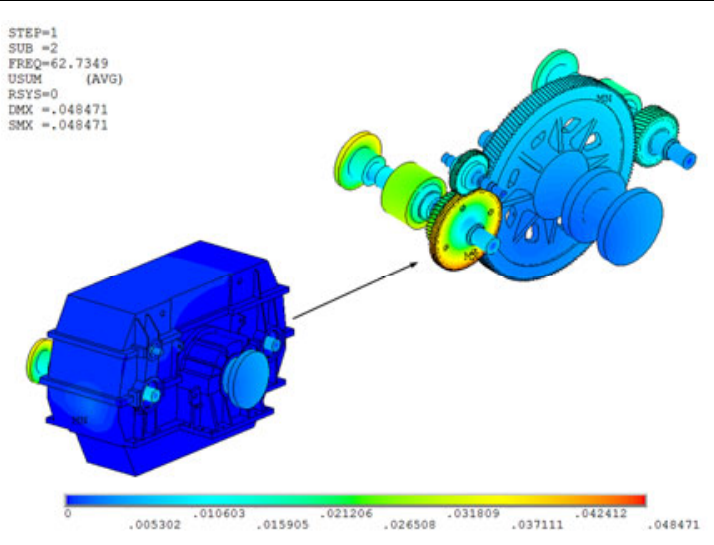

(b) Mode no. 2

Fig. 3 The first two natural mode shapes of the gear system

The marine gearbox example used in this study shows that in the first ten modes, the natural frequency is low and the low-order mode of vibration is mainly concentrated in the gear transmission system. The gear meshing frequency is $546.7 \mathrm{~Hz}$. A comparison of the 
frequency value with those of frequencies shown in Table 2 clearly illustrates that the gear meshing frequency does not overlap with any of the system frequencies; therefore, no resonance response is expected to occur for this gear system.

\section{Gear system experimental modal analysis method and its validation}

Experimental modal technique is based on the modal theory analysis and the dynamic testing technology. Accurate modal parameters can be obtained by hitting the mechanical structure and measuring its vibration response on the surface of the gearbox after having calculated a series of frequency response functions. This section will introduce the gear system experimental modal analysis method and its validation.

\subsection{The basic principle of modal fitting based on the frequency domain method}

The dynamic performance of the gearbox after discretization can be described by an $n$ order differential equation

$$
\mathbf{M} \ddot{\mathbf{x}}+\mathbf{C} \dot{\mathbf{x}}+\mathbf{K x}=\mathbf{f}(t)
$$

where $\mathbf{M}, \mathbf{C}, \mathbf{K}$ are the mass matrix, the damping matrix, and the stiffness matrix of the gear system, respectively; $\mathbf{x}, \dot{\mathbf{x}}, \ddot{\mathbf{x}}$ are the vibration displacement, the velocity, and the acceleration vector, respectively; $\mathbf{f}(t)$ is the exciting force vector.

When the initial conditions are equal to zero, the equation with the $s$ as a variable can be obtained based on the Laplace transform,

$$
\left[\mathbf{M} s^{2}+\mathbf{C s}+\mathbf{K}\right] \mathbf{X}(s)=\mathbf{F}(s)
$$

where $\left[\mathbf{M} s^{2}+\mathbf{C} s+\mathbf{K}\right]$ describes the dynamic characteristics of the gear system, namely the generalized impedance matrix $\mathbf{Z}(s)$.

The inverse matrix of the generalized impedance matrix is called a generalized admittance matrix or a transfer function matrix,

$$
\mathbf{H}(s)=\left[\mathbf{M} s^{2}+\mathbf{C} s+\mathbf{K}\right]^{-1}
$$

Substituting Eq.(3) into Eq.(2), we can get

$$
\mathbf{X}(s)=\mathbf{H}(s) \mathbf{F}(s) .
$$

When $s=j \omega$, the relationship between the output and the input force in the frequency domain can be described as

$$
\mathbf{X}(\omega)=\mathbf{H}(\omega) \mathbf{F}(\omega)
$$

where $\mathbf{H}(\omega)$ is the matrix of the frequency response function, in which $\mathbf{H}_{i j}(\omega)=\mathbf{X}_{i}(\omega) / \mathbf{F}_{j}(\omega)$ in the $i^{\text {th }}$ row and the $j^{\text {th }}$ column can be defined as the ratio of the response in the $i^{\text {th }}$ row to the excitation force when the excitation force in the $j^{\text {th }}$ column is equal to zero.

Similarly, assuming that $s=j \omega$ in the generalized admittance matrix, we can get the admittance matrix $\mathbf{Z}(\omega)=\left(\mathbf{K}-\omega^{2} \mathbf{M}\right)+j \omega \mathbf{C}$.

Assuming that $\boldsymbol{\Phi}=\left[\phi_{1}, \phi_{2}, \cdots \phi_{n}\right]$ is the matrix of modal shape and that the modal damping matrix $\mathbf{C}$ meets the orthogonality relation, we can obtain the following expressions:

$$
\left\{\boldsymbol{\Phi}^{\mathrm{T}} \mathbf{M} \boldsymbol{\Phi}=\left[\begin{array}{lll}
\ddots & & \\
& m_{r} & \\
& & \ddots
\end{array}\right] ; \boldsymbol{\Phi}^{\mathrm{T}} \mathbf{K} \boldsymbol{\Phi}=\left[\begin{array}{lll}
\ddots & & \\
& k_{r} & \\
& & \ddots
\end{array}\right] ; \boldsymbol{\Phi}^{\mathrm{T}} \mathbf{C} \boldsymbol{\Phi}=\left[\begin{array}{lll}
\ddots & & \\
& c_{r} & \\
& & \ddots
\end{array}\right]\right.
$$


where $m_{r}, k_{r}, c_{r}$ are the $r^{\text {th }}$-order modal mass, stiffness, and damping, respectively.

Substituting Eq.(6) into the impedance matrix, we can obtain

$$
\mathbf{Z}(\omega)=\boldsymbol{\Phi}^{\mathrm{T}}\left[\begin{array}{lll}
\ddots & & \\
& z_{r} & \\
& & \ddots
\end{array}\right] \boldsymbol{\Phi},
$$

in which $z_{r}=\left(k_{r}-\omega^{2} m_{r}\right)+j \omega c_{r},(r=1,2,3, \cdots, n)$.

Therefore, the matrix of the frequency response function can be described as

$$
\mathbf{H}(\omega)=\mathbf{Z}(\omega)^{-1}=\boldsymbol{\Phi}\left[\begin{array}{lll}
\ddots & & \\
& z_{r} & \\
& & \ddots
\end{array}\right] \boldsymbol{\Phi}^{\mathrm{T}}
$$

And then, the frequency response function between the coordinate $i$ and $j$ can be expressed as

$$
H_{i j(\omega)}=\sum_{r=1}^{n} \frac{\varphi_{r i} \varphi_{r j}}{\left(k_{r}-\omega^{2} m_{r}\right)+j \omega c_{r}}=\sum_{r=1}^{n} \frac{\varphi_{r i} \varphi_{r j}}{k_{r}\left(1-\lambda^{2}+j 2 \zeta_{r} \lambda_{r}\right)}
$$

Where $\omega_{r}, \zeta_{r}$ are the $r^{\text {th }}$-order modal frequency and the damping ratio, respectively.

$$
\omega_{r}=\sqrt{k_{r} / m_{r}}, \lambda_{r}=\omega / \omega_{r}, \zeta_{r}=c_{r} /\left(2 m_{r} \omega_{r}\right)
$$

Analysing the frequency response function between the coordinates $i$ and $j$, we can find out that the frequency response of an $n$-degree-of-freedom system is equal to the linear superposition of $\mathrm{n}$ single-degree-of-freedom frequency response functions. Therefore, we only need to measure the frequency response in the column for a single-input multi-output response problem in order to calculate the modal parameters $\zeta_{r}, \omega_{r}, \varphi_{r}(r=1,2, \cdots n)[11,12]$.

\subsection{Experimental modal testing method}

The experimental modal testing process of a marine gearbox mainly includes the vibration response of each measuring point, the data processing of frequency response function, the parameter fitting, the modal parameter identification, etc. Figure 4 shows the experimental modal measurement block diagram of the GW gearbox and Figure 5 shows the site of the experimental prototype testing.

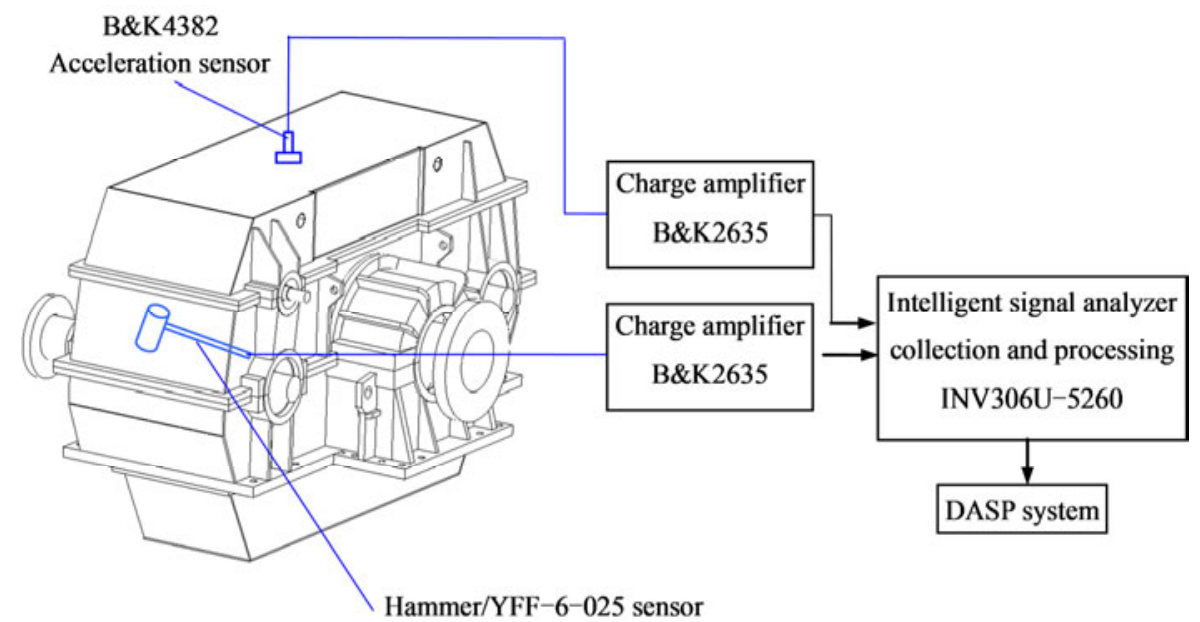

Fig. 4 Experimental modal measurement block-diagram of a GW gearbox 

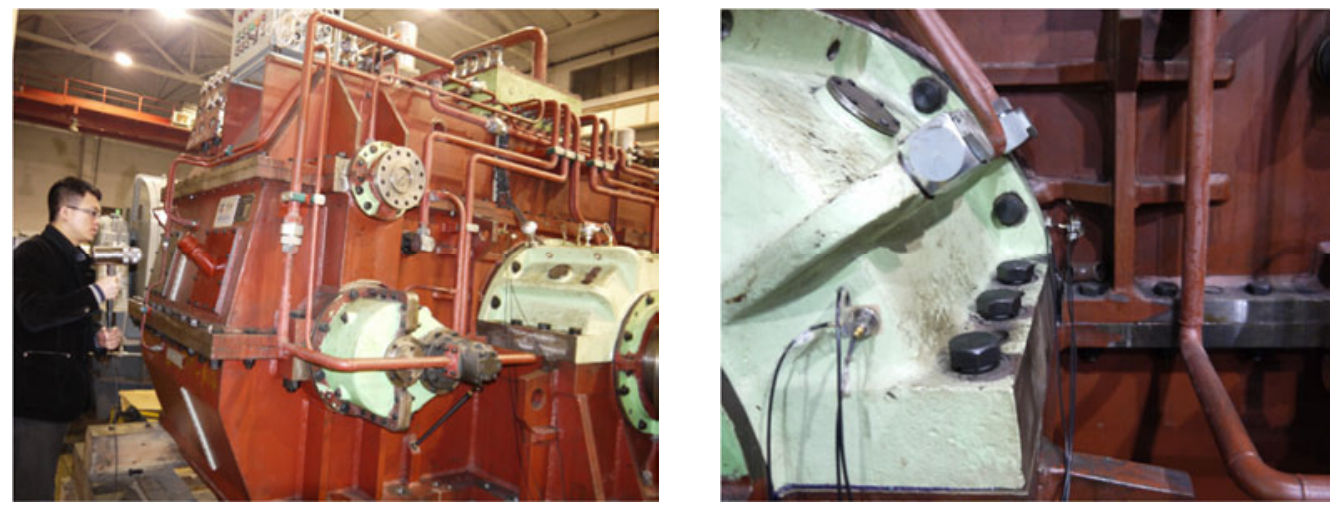

Fig. 5 The site of the marine gearbox experimental prototype testing

Through a preliminary calculation of the mode of vibration for the GW marine gearbox, we find out that each order mode of the gearbox mainly gathered in the upper and the middle gearbox. Therefore, the measuring points are designed on the upper gearbox and the middle gearbox, as shown in Fig. 6, where the coloured thread marks the position of measuring points.

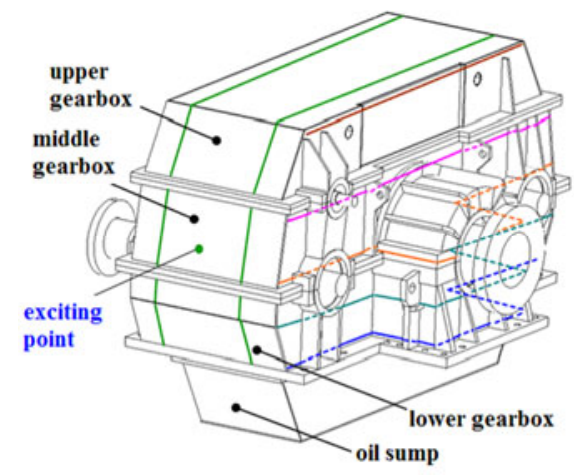

Fig. 6 Experiment layout of test points

The number of modal measuring points in the experiment is 300 points, including 120 points on the surface of the input and the output side of the gearbox, respectively, and 60 points around the top, on the left and the right side of the gearbox. The modal analysis procedure settings are as follows: uniform windowing for the input signal and exponential windowing for the output signal; the number of measurements for linear averaging is five; the sampling frequency is $5000 \mathrm{~Hz}$. The transfer functions of the gear system can be obtained using the DASP V10 software to process the measurement data [13]. Then, according to the peak points of the transfer function curves, we can determine the number of modal order by the averaging based ensemble method. Finally, the modal parameters of this marine gear system can be obtained through modal fitting by the GLOBAL method which is based on the least-square complex frequency-domain (LSCF) method [14].

\subsection{Experimental modal test results}

Figure 7 shows vertical vibration signals (the input exciting force time-domain signal, the output response time-domain signal, the transfer function curve, and the correlation coefficient) of the bearing in the input end face of the GW gearbox.

The results indicate that the coherence coefficient is greater than 0.85 in the frequency range from $0 \mathrm{~Hz}$ to $1400 \mathrm{~Hz}$. Modal parameters can be obtained based on the experimental modal test in the field of large-scale complicated mechanical systems although the coherence coefficient is not close to 1 . 


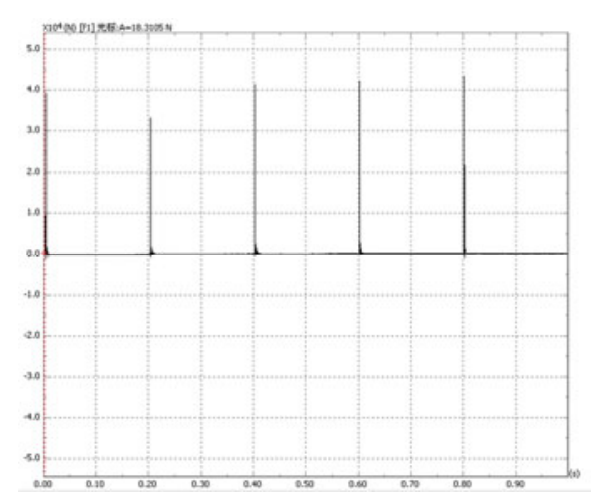

(a) input exciting force
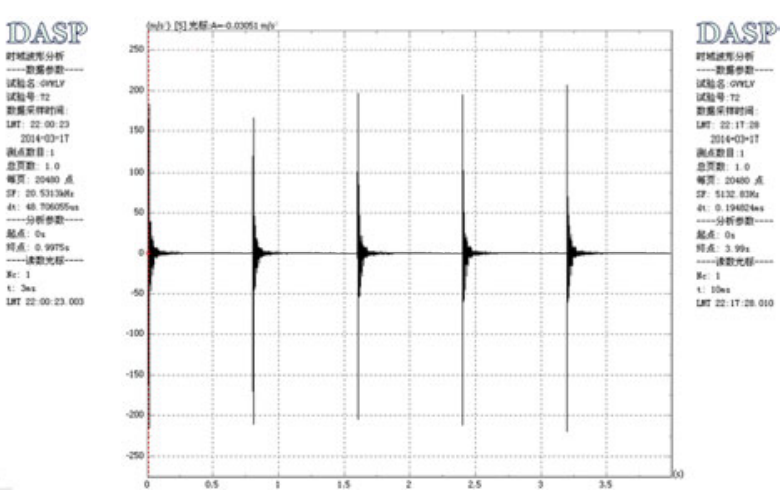

(b) output response

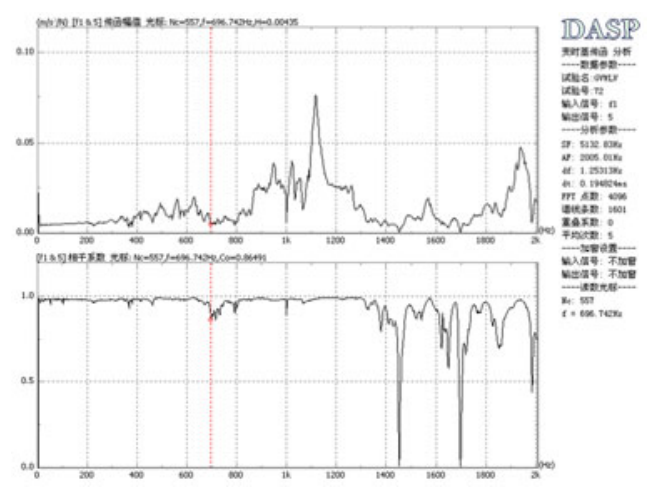

(c) transfer function curve and the correlation coefficient

Fig. 7 Vertical vibration response of the bearing in the input end face of the GW gearbox

Combining the transfer function curves of all measuring points, the frequencies of the marine gear system can be obtained through modal fitting based on the GLOBAL method. The frequency response function curve can be obtained based on averaging, one of the ensemble methods, as shown in Fig. 8.

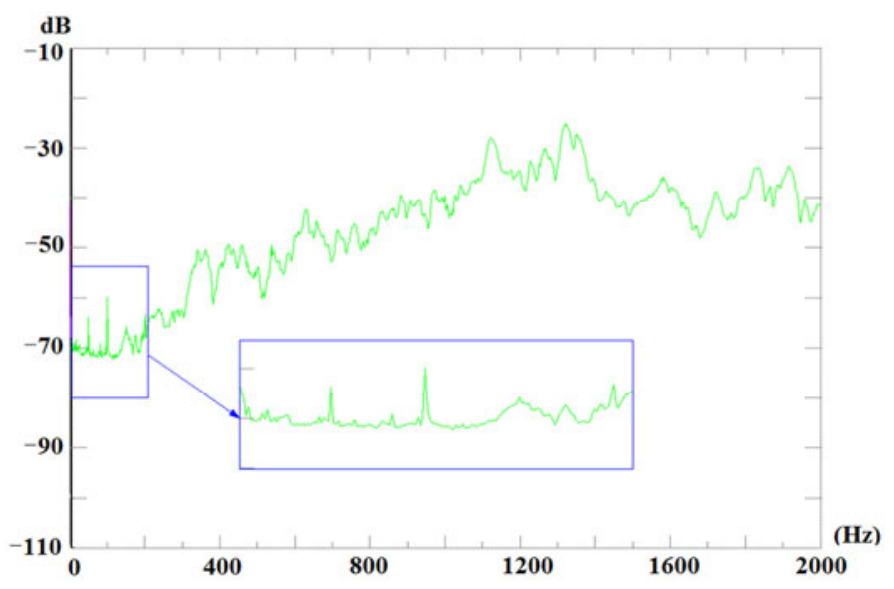

Fig. 8 The frequency response function curve

Table 3 shows a comparison of calculated values and the values obtained from the test. It can be clearly seen from the result that the calculated values of modes no.1, 5, 7, and 8 are mainly concentrated in the gear transmission system. The experimental modal analysis results cannot fully reflect all modes of the transmission system of the marine gearbox because of its large physical dimensions and a complex vibration mechanism. Other results obtained by measurements carried out during the test are in good agreement with the computational results, with a maximum error of $6.3 \%$. 
Marine Gearbox Featuring Confluence Transmission

Table 3 Natural frequencies of the gear system

\begin{tabular}{|c|c|c|c|c|c|c|c|c|c|c|}
\hline Mode no. & 1 & 2 & 3 & 4 & 5 & 6 & 7 & 8 & 9 & 10 \\
\hline $\begin{array}{c}\text { Measured values of } \\
\text { frequency }(f / \mathrm{Hz})\end{array}$ & - & 61.4 & 75.2 & 80.2 & - & 100.3 & - & - & 125.3 & 136.8 \\
\hline $\begin{array}{c}\text { Calculated values of } \\
\text { frequency }(f / \mathrm{Hz})\end{array}$ & 14.7 & 62.7 & 79.9 & 81.5 & 89.1 & 105.0 & 112.4 & 113.6 & 126.4 & 132.4 \\
\hline error $/ \%$ & - & 2.1 & 6.3 & 1.6 & - & 4.7 & - & - & 0.9 & 3.2 \\
\hline
\end{tabular}

\section{Conclusions}

(1) An approach to calculating vibration modal characteristic of a GW marine gear system based on the theoretical and the experimental modal analysis is given in view of the facts that it is difficult to accurately determine modal data because of the complex vibration mechanism of the system.

(2) The experimental modal analysis results failed to fully reflect all modes of the marine gearbox transmission system because of its large physical dimensions and a complex vibration mechanism. Other results obtained by measurements carried out in the test are in good agreement with the computational results, with a maximum error of $6.3 \%$.

\section{Acknowledgements}

The authors are grateful for the financial support provided by Chongqing Research Program of Basic Research and Frontier Technology No.cstc2016jcyjA0514 and No.cstc2017jcyjAX0053, Project Foundation of Municipal Education Committee of Chongqing under Contract No. KJ1600503 and No.KJ1600534, State Key Laboratory of Mechanical Transmission Project NO. SKLMT-KFKT-201706, Chongqing Postdoctoral Project Xm2017191, China Postdoctoral Project 2018M633626XB, National Engineering Laboratory for Highway Maintenance Equipment under Contract No. 310825161104. The CN Gpower Gearbox Co., Ltd of P. R. China should be thanked for providing the test site of the marine gear system.

\section{REFERENCES}

[1] Inalpolat M., Kahraman A, 2008, Dynamic modeling of planetary gears of automatic transmissions. Proceedings of the Institution of mechanical engineers, Part K: Journal of multi-body dynamics, 222, 229242.

[2] Tugan E., Parker R. G, 2009, Modal properties of three-dimensional helical planetary gears. Journal of sound and vibration, 325, 397-420. https://doi.org/10.1016/j.jsv.2009.03.002

[3] W. Shiyu, W. Jian, C. Shuqian, 2011, Modal properties for bevel planetary gear trains. Journal of Vibration Engineering, 4, 376-384.

[4] M. Hui, Z. Lisha, W. Qibing, 2012, Modal Coupling Characteristic Analysis of a Helical Gear Rotor System With Parallel Shafts. Proceedings of the CSEE, 29 ,131-136.

[5] B. Zhonghong, L. Geng, W. Liyan, 2012, Modal analyses of herringbone planetary gear train with journal bearings. Mechanism and Machine Theory, 54, 99-115. https://doi.org/10.1016/j.mechmachtheory.2012.03.006

[6] H. Xi, L. Runfang, L. Tengjiao, 2002, Joint structure parameter identification for lateral bending vibration of gear Shaft. Machine Design and Research, 2, 31-33.

[7] X. Xiangyang, Z. Caichao, Z. Xiaorong, 2011, Experimental modal analysis of heavy duty marine gearbox. Journal of Vibration and Shock, 7, 266-270.

[8] Ericson T. M., Parker R. G, 2013, Planetary gear modal vibration experiments and correlation against lumped-parameter and finite element models. Journal of Sound and Vibration, 332, 2350 2375.

https://doi.org/10.1016/j.jsv.2012.11.004 
[9] H. Zeyin, L. Tianhong, X. Xiangyang, 2016, An approach to calculate radiation noise of gear system. Journal of Vibroengineering, 1, 649-660.

[10] L. Tengjiao, S. Jianjun, H. Zeyin, et al, 2014, Software copyright: Thermal-elastic deformation and modification analysis of gear pairs.

[11] Ewins, D. J, 1984, Modal testing: theory and practice, Research Studies Press.

[12] F. Zhifang, H. Hongxing, 2000, Modal analysis: theory and practice, Shanghai Jiaotong University Press.

[13] DASP E.T., 2010, Data acquisition and signal processing engineering technology manual, China Orient Institute of Noise \& Vibration.

[14] Z. Lili, Y. Zhihong, Application of the Global Method in Lathe Modal Parameter Estimation, Machine Design and Manufacturing Engineering, 2011, 40(1):61-64.

Submitted: $\quad 28.12 .2017$

Accepted: $\quad$ 10.7.2018
Zeyin $\mathrm{He}$

School of Mechantronics \& Vehicle

Engineering, Chongqing Jiaotong

University

No.66 Xuefu Road, Nan'an District,

Chongqing 400074, China

Tang Weiyi

School of Mechantronics \& Vehicle

Engineering, Chongqing Jiaotong

University

No.66 Xuefu Road, Nan'an District,

Chongqing 400074, China

Tengjiao Lin

State Key Laboratory of Mechanical

Transmission, Chongqing University

No.174 Shazhengjie, Shapingba,

Chongqing 400044, China

Sun Shizheng

School of Mechantronics \& Vehicle

Engineering, Chongqing Jiaotong

University

No.66 Xuefu Road, Nan'an District,

Chongqing 400074, China 